\title{
Perbandingan Metode Ekstraksi Zat Warna Dari Rumput Laut Sargassum sp
}

\author{
Rita Febriani, Agrippina Wiraningtyas*, Ruslan, Nurfidianty Annafi
}

Program Studi Pendidikan Kimia STKIP Bima

Jl. Tendean No.1 Mande Kota Bima

*Email : agriwiraningtyas@gmail.com

\begin{abstract}
ABSTRAK
Rumput laut Sargassum sp merupakan salah satu spesies rumput laut yang mengandung senyawa fukosatin, klorofil, dan karotenoid yang berperan sebagai zat warna. Pelarut yang digunakan dalam ekstraksi adalah pelarut air yang memiliki tingkat kepolaran yang tinggi.sehingga pada penelitian kali ini bertujuan untuk mengetahui pengaruh metode ekstraksi ekstrak rumput laut Sargassum sp terhadap zat warna alami. Metode pada penelitian kali ini untuk mendapatkan zat warna alami pada rumput laut sargassum sp yaitu dengan metode maserasi dan metode refluks menggunakan pelarut air. Hasil ekstraksi kemudian diukur dengan spektrofotometer UV-VIS pada panjang gelombang 190$400 \mathrm{~nm}$, ekstraksi menghasilkan warna coklat muda pada metode maserasi, dan warna coklat pekat pada metode refluks. Kemudian dilakukan analisis data dengan membuat tabel dan diagram menggunakan aplikasi Microsoft excel. Hasil penelitian ini adalah metode maserasi merupakan metode yang efektif untuk mengekstraksi zat warna dari rumput laut sargassum sp dibandingkan dengan metode refluks, dimana metode maserasi menghasilkan warna coklat muda dengan panjang gelombang $203 \mathrm{~nm}$ dengan nilai absorbansi 3, 883. Sedangkan metode refluks menghasilkan warna coklat pekat dengan panjang gelombang $199 \mathrm{~nm}$ yang menghasilkan absorbansi 3,745.
\end{abstract}

Kata Kunci : Maserasi, Refluks, Sargassum sp, zat warna, pelarut air

\section{PENDAHULUAN}

Sumber pewarna alami adalah tumbuhan dan mikroorganisme (Aberoumand, 2011). Pewarna alami merupakan zat warna yang berasal dari ekstrak tumbuhan dan digunakan sebagai alternatif pewarna yang tidak toksik, dapat diperbaharui, mudah terdegradasi dan ramah lingkungan (Yernisa dkk., 2013). Zat warna alam merupakan zat warna yang diperoleh dari alam, baik secara langsung maupun tidak langsung dan dapat diperoleh dari bagian tanaman seperti kulit batang, daun, buah, akar, bunga, biji, atau umbinya. Zat warna alam dapat diperoleh dari tanaman yang berupa pigmen (Fadilah dkk, 2020). Beberapa jenis pigmen yang ada di sekitar kita diantaranya berupa klorofil pada daun berwarna hijau, karotenoid, tanin dan antosianin (Simanjuntak \& Sinaga, 2014). Salah satu pigmen yang bisa dimanfaatkan untuk sumber pewarnaan terdapat pada rumput laut Sargassum sp.

Rumput laut Sargassum sp adalah salah satu genus dari kelompok rumput laut coklat yang merupakan generasi terbesar dari famili sargassaceae. Sargassum sp banyak mengandung algin, tannin dan phenol yang banyak dimanfaatkan dalam industri farmasi dan kosmetik. Selain itu, Sargassum sp biasanya dicirikan oleh tiga sifat yaitu adanya pigmen coklat yang menutupi warna hijau, fotosintesis terhimpun dalam bentuk laminaran, dan dapat menghasilkan algin atau alginat, selulosa, fikoidin, dan manitol yang komposisinya sangat tergantung pada jenis (spesies), masa perkembangan dan kondisi tempat tumbuhnya (Maharani \& Widyayanti, 2010). Selama ini alga jenis Sargassum sp hanya dibiarkan menjadi sampah lautan, hanyut terbawa arus atau terdampar di pinggir pantai dan belum dibudidayakan, salah satunya yang tumbuh di Pantai Wane Kabupaten Bima (Amir dkk. 2016). Ada beberapa proses teknologi yang dapat digunakan untuk pengambilan zat warna alam dari sumbernya, salah satunya dengan metode ekstraksi (Prayitno dkk., 2005). 
Ekstraksi merupakan suatu metode yang digunakan untuk mengeluarkan satu komponen campuran dari zat padat dengan bantuan zat cair sebagai pelarut (Murbantan dkk., 2009). Ada beberapa metode ekstraksi tetapi yang biasa digunakan adalah metode maserasi, dan refluks. Metode maserasi adalah proses perendaman sampel untuk menarik komponen yang diinginkan dengan kondisi dingin diskontinyu (Ruslan, 2019). Metode refluks adalah ekstraksi dengan pelarut pada temperatur titik didihnya, selama waktu tertentu dan jumlah pelarut terbatas yang relatif konstan dengan adanya pendingin balik. Metode tersebut membutuhkan pelarut sebagai bahan pelarut yang digunakan dalam proses ekstraksi zat warna, salah satu pelarut polar yang efektif dan umum digunakan yaitu pelarut air.

Pelarut air adalah substansi kimia dengan rumus kimia $\mathrm{H}_{2} \mathrm{O}$ yang merupakan suatu pelarut penting, karena memiliki kemampuan untuk melarutkan banyak zat kimia (Wiraningtyas, 2019). Zat kimia yang dapat dilarutkan dengan pelarut air yaitu garamgaram, gula, asam, beberapa jenis gas, dan banyak macam molekul organik karena merupakan pelarut polar yang memiliki gugus hirdroksil (OH) (Ruslan dkk, 2020). Dimana gugus hidroksil pada air berpartisipasi ke dalam ikatan hidrogen sehingga membuat cair dan lebih sulit menguap dari pada senyawa organik lainnya yang memiliki massa molekul yang sama, sehingga hal ini dapat mengekstrak zat warna alam yang bersifat polar dengan baik. Berdasarkan uraian tersebut di atas maka perlunya dilakukan penelitian tentang perbandingan metode yang digunakan untuk mengekstraksi zat warna dari rumput laut Sargassum sp, sehingga dapat diketahui metode paling efektif dalam ekstraksi zat warna dari rumput laut Sargassum sp.

\section{METODE}

Prosedur penelitian ini dilakukan melalui beberapa tahap kegiatan sebagai berikut:

a. Persiapan sampel

Sampel diambil dari pantai Wane Kabupaten Bima berupa rumput laut Sargassum sp dalam bentuk basah. Dicuci sampai bersih dan dikeringkan. Setelah proses pengeringan selesai tahap selanjutnya adalah penggilingan untuk mendapatkan serbuk rumput laut.

b. Tahap ekstraksi metode maserasi rumput laut Sargassum sp

Pembuatan ekstrak rumput laut Sargassum sp dilakukan dengan cara maserasi dengan menimbang 50 gram serbuk rumput laut Sargassum sp dimasukkan ke dalam labu erlenmeyer lalu ditambahkan pelarut air ke dalam erlenmeyer sebanyak $350 \mathrm{ml}$ dan disimpan selama 4 jam. Kemudian disaring menggunakan kertas saring whatman. Ekstrak yang didapatkan lalu diuapkan dengan suhu $50-60^{\circ} \mathrm{C}$ didapatkan ekstak kental lalu ditimbang dengan berat 0,02 gram lalu diencerkan dengan $100 \mathrm{ml}$ aquades kemudian diuji dengan menggunakan spektrofotometer UV - Vis.

c. Tahap ekstraksi metode refluks rumput laut Sargassum sp

Pembuatan ekstrak rumput laut Sargassum sp dilakukan dengan cara refluks dengan menimbang 50 gram serbuk rumput laut Sargassum sp dimasukkan ke labu leher tiga lalu ditambahkan pelarut air ke dalam labu leher tiga sebanyak $350 \mathrm{ml}$ dan didestilasi selama 4 jam. Didinginkan kemudian disaring menggunakan kertas saring whatman, ekstrak yang didapatkan lalu diuapkan dengan suhu $50-60^{\circ} \mathrm{C}$ didapatkan ekstrak kental lalu ditimbang dengan berat 0,02 gram lalu diencerkan dengan $100 \mathrm{ml}$ aquades kemudian diuji dengan menggunakan spektrofotometer UV - Vis.

\section{HASIL DAN PEMBAHASAN}

Penelitian ini dilakukan dengan membandingkan metode ektraksi yaitu metode maserasi dan metode refluks dengan sampel ekstrak zat warna rumput laut Sargassum sp menggunakan pelarut air. Hasil ekstraksi zat warna dari rumput laut Sargassum sp dengan menggunakan metode maserasi dan refluks dapat diperoleh dari hasil pengukuran absorbansi menggunakan Spektrofotometer UV-Vis pada panjang gelombang antara 190- 
$400 \mathrm{~nm}$. Metode maserasi dilakukan dengan cara merendam serbuk simplisia dengan menggunakan pelarut air selama 4 jam lalu disaring dan diuapkan sampai menghasilkan ekstrak kental dan diuji menggunakan spektrofotometer UV-Vis. Sedangkan metode refluks dilakukan dengan memasukan serbuk simplisia ke dalam labu leher tiga dengan menggunakan pelarut air dan didestilasi selama 4 jam lalu didinginkan kemudian disaring dan diuapkan sampai menghasilkan ekstrak kental dan diuji menggunakan spektrofotometer UV-Vis. Adapun hasil penelitian yang diperoleh dapat dilihat pada tabel 1.

Tabel 1 Hasil Absorbansi dari Ekstrak Rumput Laut Sargassum sp

\begin{tabular}{|c|c|c|}
\hline \multirow{2}{*}{$\begin{array}{c}\text { Panjang } \\
\text { gelombang }(\mathrm{nm})\end{array}$} & \multicolumn{2}{|c|}{ Absorbansi $(\mathrm{A})$} \\
\cline { 2 - 3 } & Maserasi & Refluks \\
\hline 196 & 2.822 & 3.497 \\
\hline 197 & 3.079 & 3.664 \\
\hline 198 & 3.368 & 3.663 \\
\hline 199 & 3.653 & 3.745 \\
\hline 200 & 3.505 & 3.608 \\
\hline 201 & 3.588 & 3.563 \\
\hline 202 & 3.779 & 3.527 \\
\hline 203 & 3.883 & 3.528 \\
\hline 204 & 3.869 & 3.465 \\
\hline 205 & 3.770 & 3.398 \\
\hline 206 & 3.760 & 3.330 \\
\hline
\end{tabular}

Berdasarkan data perbandingan absorbansi metode ekstraksi di atas maka metode yang paling tinggi nilai absorbasi adalah metode maserasi dibandingkan metode refluks. Berikut adalah gambar grafik hasil pengukuran dengan spektrofotometer UV-Vis dengan metode ekstraksi.

\section{Pembahasan}

\section{Tahap Preparasi Sampel (Rumput Laut Sargassum sp.)}

Rumput laut Sargassum sp. segar dicuci untuk menghilangkan air laut dan garam yang tertinggal agar tidak mengganggu ekstrak yang dihasilkan. Selanjutnya, rumput laut Sargassum sp yang telah bersih dikeringkan dengan cara dianginkan. Hal ini dilakukan untuk mengurangi kadar air yang ada dalam sampel agar lebih tahan lama saat disimpan, dan juga menghindari terjadinya kerusakan sampel yang disebabkan oleh mikroorganisme atau bakteri. Pengeringan juga bertujuan agar kadar air dalam sampel tidak mengganggu hasil ekstrak yang didapatkan. Setelah itu Sargassum sp. dipotong kecil dan diblender. Hal ini dilakukan karena ukuran bahan termasuk dalam faktor penentu ekstraksi yang tidak diukur, sehingga tiap perlakuan ukuran sampel harus sama (Rohmaniyah, 2016). Proses tersebut menghasilkan serbuk kering rumput laut Sargassum sp berwarna cokelat.

\section{Pengaruh Perbandingan Metode Ekstraksi Terhadap Zat Warna Rumput Laut Sargassum sp}

Zat warna alami ini diperoleh dengan cara ekstraksi pada perbandingan metode ekstraksi, metode yang paling efektif untuk mendapatkan hasil ekstrak yang paling baik dilakukan dengan 2 metode yaitu metode maserasi dan metode refluks. Hasil absorbansi dapat dilihat pada tabel 1 . Metode ekstraksi yang dapat digunakan untuk mengekstraksi zat warna alami adalah metode maserasi dan metode refluks. Dari tabel 1 di atas menunjukan bahwa adanya perbedaan antara metode maserasi dan metode refluks yang telah dilakukan dalam penelitian ini. Bahwa metode maserasi menghasilkan warna coklat muda dengan panjang gelombang $203 \mathrm{~nm}$ yang menghasilkan absorbansi 3,883. Sedangkan metode refluks menghasilkan warna coklat pekat dengan panjang gelombang $199 \mathrm{~nm}$ yang menghasilkan absorbansi 3,745. Dari tabel 1 tersebut terlihat adanya perbedaan dari kedua 
metode ekstraksi tersebut. Hal ini dikarenakan kedua metode ekstraksi tersebut merupakan metode ekstraksi yang berbeda. Dimana metode maserasi dilakukan tanpa proses pemanasan sedangkan metode refluks dilakukan dengan proses pemanasan, sehingga akan diperoleh hasil ekstrak yang berbeda seperti yang terlihat pada tabel 1 . Untuk melihat lebih jelas adanya pengaruh dari kedua metode ekstraksi terhadap zat warna rumput laut Sargassum sp dapat dilihat pada gambar 1 berikut. Dari diagram tersebut dapat dilihat bahwa adanya perbandingan dari kedua metode ekstraksi yang digunakan.

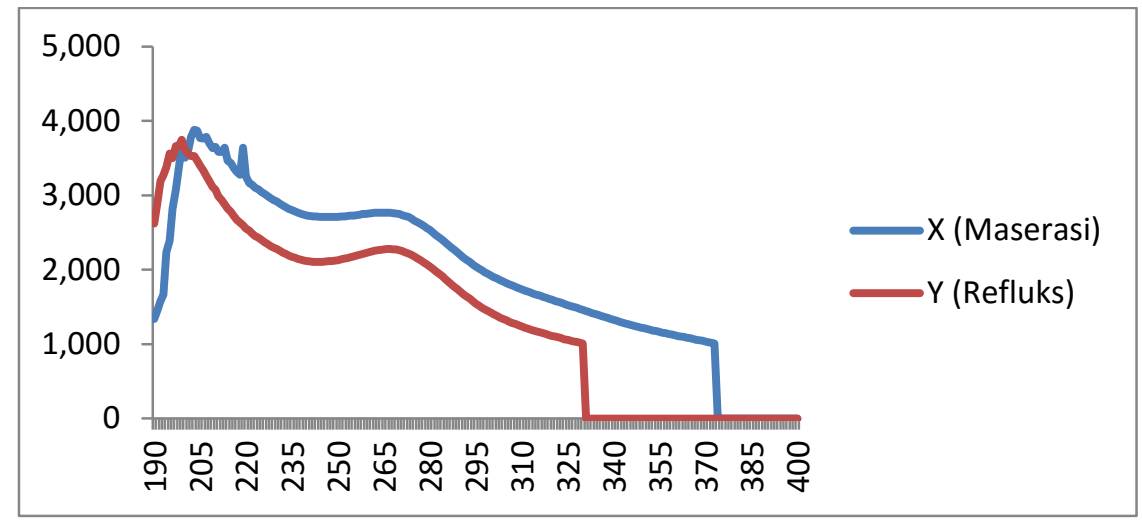

Gambar 1. Grafik perbandingan absorbansi metode maserasi dan refluks

Data pada gambar 1 juga memperlihatkan terjadinya pergeseran panjang gelombang dari puncak absorbansi, yaitu $199 \mathrm{~nm}$ ke 203 nm, yang terjadi seiring meningkatnya suhu pemanasan selama 4 jam. Dari data tersebut dapat disimpulkan bahwa metode yang paling efektif adalah metode maserasi, karena metode maserasi menghasilkan nilai absorbansi yang lebih tinggi dibandingkan metode refluks yaitu dengan nilai absorbansi 3,883.

\section{KESIMPULAN}

Berdasarkan penelitian yang telah dilakukan dapat disimpulkan metode yang paling efektif untuk mengekstraksi zat warna dari rumput laut Sargassum sp adalah metode maserasi, karena metode maserasi menghasilkan nilai absorbansi yang lebih tinggi yaitu 3.883 pada panjang gelombang $203 \mathrm{~nm}$. Sedangkan menggunakan metode refluks menghasilkan nilai absorbansi 3,745 pada panjang gelombang $199 \mathrm{~nm}$.

\section{DAFTAR PUSTAKA}

Aberoumand, A. 2011. A Review Article on Edible Pigments Properties and Sources as Natural Biocolorants in Foodstuff and Food Industry. World J Dairy Food Sci, 6(1): 71-78.

Amir, A., Wiraningtyas, A., Ruslan, R., \& Annafi, N. (2016). Perbandingan Metode Ekstraksi Natrium Alginat: Metode Konvensional dan Microwave Assisted Extraction (MAE). CHEMPUBLISH JOURNAL, 1(2), 7-13.

Fadilah, R., \& Annafi, N. EKSTRAKSI ZAT WARNA DARI RUMPUT LAUT Sargassum sp MENGGUNAKAN PELARUT METHANOL. Jurnal Redoks: Jurnal Pendidikan Kimia dan IImu Kimia ISSN, 2614, 7300.

Maharani MA, Widyayanti. 2010. Pembuatan alginat dari rumput laut untuk menghasilkan produk dengan rendemen dan viskositas yang tinggi. Universitas Dipenogoro.

Masojidek J. M., Koblizek dan G., Torzila. 2004. Photosynthesis in Microalgae in: A Richmond (Ed), Handbookof Microalgal Culture: Boitechnology and Applied Phycology, Blakwell Science Ltd., lowa, p. 20-39.

Murbantan, Anwar Mustafa, Mochamad Rosjidi, H. S. 2009. Proses Ekstrasi dan Powderisasi Zat Warna Alam. Badan Pengkajian dan Penerapan Tekhnologi, Jakarta.

Prayitno, R. E., Wijana, S., \&D, B. S. D. 2005.Pengaruh Bahan Fiksasi Terhadap Ketahanan 
Luntur dan Intensitas Warna Kain Mori Batik Hasil Pewarnaan Daun Alpukat (PerseaamericanaMill.) The Influence of Fixation To The Fastness And Color Intensity of Batik Calico of Avocado Leaves Coloration. Fakultas Teknologi Pertanian,Universitas Brawijaya.

Rohmaniyah, M. 2016. Uji Antioksidan Ekstrak Etanol 80\% dan Fraksi Aktif Rumput Bumbu (Lophatherum gracile Brongn) Menggunakan Metode DPPH serta Identifikasi Senyawa Aktifnya. Malang: UIN Maulana Malik Ibrahim.

Ruslan, R., Agustina, S., \& Hasanah, U. (2019). Penentuan Nilai Sun Protection Factor (SPF) dari Kulit Bawang Merah. JURNAL REDOKS: JURNAL PENDIDIKAN KIMIA DAN ILMU KIMIA, 2(01), 34-43.

Ruslan, R., \& Agustina, S. (2020). UJI KESTABILAN PENYIMPANAN EKSTRAK ZAT WARNA ALAMI DARI RUMPUT LAUT Sargassum sp. JURNAL REDOKS: JURNAL PENDIDIKAN KIMIA DAN ILMU KIMIA, 3(1), 1-7.

Simanjuntak, L., \& Sinaga, C. 2014. Ekstraksi Pigmen Antosianin Dari Kulit Buah Naga Merah ( Hylocereus polyrhizus ). Jurnal Teknik Kimia USU, 3(2 Juni), 25-29.

Yernisa, Gumbira-Sa'id, E. dan Syamsu, K. 2013. Aplikasi Pewarna Bubuk Alami dari Ekstrak Biji Pinang (Areca catechu L.) pada Pewarnaan Sabun Transparan. Jurnal Teknologi Industri Pertanian, 23 (3): 190-198

Wiraningtyas, A. (2019). EKSTRAKSI ZAT WARNA DARI RUMPUT LAUT Sargassum sp. JURNAL REDOKS: JURNAL PENDIDIKAN KIMIA DAN ILMU KIMIA, 2(01), 1-10. 